\title{
БИОЛОГИЧЕСКИЕ СВОЙСТВА
}

MYCOBACTERIUM TUBERCULOSIS

И ХАРАКТЕРИСТИКА ВОСПАЛИТЕЛЬНОГО

ОТВЕТА ПРИ ИНФИЛЬТРАТИВНОМ

ТУБЕРКУЛЕЗЕ ЛЕГКИХ

\author{
О.Т. Титаренко, М.Е. Дьякова, О.А. Маничева, Д.С. Эсмедляева, М.З. Догонадзе, \\ Н.П. Алексеева, Т.Л. Перова, Н.Н. Мельникова
}

ФГБУ Санкт-Петербургский НИИ фтизиопульмонологии МЗ РФ, Санкт-Петербург, Россия

Резюме. Характер взаимоотношений «хозяин-патоген» анализируется по результатам обследования 42 больных с впервые выявленным нелеченым инфильтративным туберкулезом легких и с учетом биологических свойств микобактерий туберкулеза (МБТ) и биомаркеров воспалительной реакции - белков острой фазы (БОФ). В качестве группирующих признаков использованы генотипы МБТ (Beijing и иные) и результаты трехмесячной противотуберкулезной терапии. В случаях выделения МБТ генотипа Beijing чаще регистрируется их множественная лекарственная устойчивость и большая распространенность поражения легких и ассоциированность цитотоксичности МБТ с эффективностью терапии. Установлено, что больным со значительным клинико-рентгенологическим улучшением после трехмесячной терапии свойственны исходные (до лечения) уровни БОФ в пределах референтных значений. Установлено, что выделенная в ходе дискриминантного анализа констелляция четырех БОФ (гаптоглобин, церулоплазмин, эластаза, аденозиндезаминаза) обладает сходной прогностической эффективностью независимо от генотипа МБТ. Полученные данные указывают на большее значение в анализируемой системе составляющей «хозяин», отражающей ответ организма на индуцируемый МБТ воспалительный процесс.

Ключевые слова: туберкулез, белки острой фазы, генотип, вирулентность.

\section{Введение}

В исследованиях, посвященных взаимоотношению организма больного и возбудителя в ходе возникновения и эволюции туберкулезного процесса, до сих пор приоритет отдается изучению свойств одной из составляющих системы хозяин-патоген - возбудителю [6, 14].
Такой подход оправдан убедительными доказательствами значимости биологических свойств Mycobacterium tuberculosis (МБТ), в первую очередь вирулентности и лекарственной устойчивости (ЛУ), для прогноза течения и исхода туберкулезного процесса в легких [1, 24, 27]. В последние годы выявлены многие генетические детерминанты патогенности МБТ [17,

\footnotetext{
Авторы:

Титаренко О.Т., к.М.Н., зав. лабораторией патогенетических исследований ФГБУ СПб НИИФ МЗ РФ, Санкт-Петербург, Россия; Дьякова М.Е., к.б.н., старший научный сотрудник лаборатории патогенетических исследований ФГБУ СПб НИИФ МЗ РФ, Санкт-Петербург, Россия;

Маничева О.А., д.б.н., ведущий научный сотрудник лаборатории этиологической диагностики ФГБУ СПб НИИФ МЗ РФ, Санкт-Петербург, Россия;

Эсмедляева Д.С., к.б.н., старший научный сотрудник лаборатории патогенетических исследований ФГБУ СПб НИИФ МЗ РФ, Санкт-Петербург, Россия;

Догонадзе М.З., к.б.н., старший научный сотрудник лаборатории этиологической диагностики ФГБУ СПб НИИФ МЗ РФ, Санкт-Петербург, Россия;

Алексеева Н.П., к.Ф.-м.Н., программист отдела научно-технической информации ФГБУ СПб НИИФ МЗ РФ, Санкт-Петербург, Россия; Перова Т.Л., научный сотрудник лаборатории патогенетических исследований ФГБУ СПб НИИФ МЗ РФ, Санкт-Петербург, Россия; Мельникова Н.Н., К.М.Н., старший научный сотрудник лаборатории этиологической диагностики ФГБУ СПб НИИФ МЗ РФ, Санкт-Петербург, Россия.
}

\section{Адрес для переписки:}

Титаренко Ольга Тимофеевна

194064, Россия, Санкт-Петербург, ул. Политехническая, 32

Тел.: (812) 297-86-31. Факс: (812) 297-16-26.

E-mail: olga-titarenko39@yandex.ru поступила в редакцию 22.11.2013 отправлена на доработку 23.11.2013 принята к печати 05.05.2014

() Титаренко О.Т. и соавт., 2014 
22, 23, 28, 30]. Ряд исследователей указывает на большую вирулентность МБТ семейства Beijing, которому свойственна и большая частота встречаемости ЛУ, что определяет худшие результаты химиотерапии препаратами 1-го ряда в случаях, вызванных МБТ этого типа [5, $16,18,29]$.

В то же время на втором плане оказались вопросы, относящиеся ко второй составляющей системы «хозяин-патоген». Организм больного закономерно отвечает на инфекционный агент воспалительной реакцией, выраженность которой определяется как интенсивностью воздействия возбудителя, так и возможностями механизмов защиты. В качестве маркеров воспалительной реакции принято использовать различные биохимические показатели. Последние относятся преимущественно к категории так называемых белков острой фазы воспаления (БОФ), которые отличаются полифункциональностью и характеризуют различные этапы системного воспалительного ответа [2, 4, 8, 9].

Значимость возбудителя, его биологических свойств в формировании системы «патогенхозяин» несомненна, однако приоритет должен быть отдан исследованию различий течения инфекционного процесса на уровне макроорганизма, как ведущего компонента во взаимоотношениях макро- и микроорганизма [7, 11, 19]. С указанных позиций представляется актуальной оценка адекватности ответа организма больного, определяемой адаптационными возможностями защитных механизмов, на агрессию возбудителя с учетом свойств патогена.

Целью настоящего исследования явилось изучение соотношения маркеров воспалительного ответа и течения процесса у больных инфильтративным туберкулезом легких (ИТЛ) в зависимости от генотипа и других свойств МБТ.

\section{Материалы и методы}

Обследовано 42 больных (26 мужчин и 16 женщин) с впервые выявленным нелеченным ИТЛ в возрасте 18-74 лет (медиана - 28,5). У всех больных при поступлении бактериовыделение МБТ было зарегистрировано методом посева на плотные среды (Левенштейна-Иенсена и Финна-2) и/или на жидкую среду (Миддлбрука 7Н9) в автоматизированной системе ВАСТЕС MGIT 960 (Becton Dickinson, USA).

Экспресс-диагностику множественной лекарственной устойчивости (МЛУ) МБТ для назначения адекватной противотуберкулезной терапии проводили с использованием биологических микрочипов «ТБ-Биочип-1» (ИМБ РАН) для выявления ДНК МБТ в клиническом материале и определения мутаций, ассоциированных с лекарственной устойчивостью к ри- фампицину (ген rpoB) и изониазиду (гены kat $\mathrm{G}$, $\operatorname{inh} \mathrm{A}, \operatorname{ahpC)}$. Лекарственную устойчивость МБТ к противотуберкулезным препаратам определяли в автоматизированной системе ВАСТЕС MGIT 960, согласно рекомендациям производителя (Becton Dickinson, USA) и непрямым методом абсолютных концентраций на плотной среде Левенштейна-Йенсена в соответствии с Приказом № 109. Сполиготип изолятов определен методом Kamerbeek et al. [21] сотрудниками лаборатории молекулярной микробиологии ФГУН НИИ эпидемиологии и микробиологии имени Пастера (зав. лабораторией - д.м.н., проф. О.В. Нарвская).

Массивность бактериовыделения (МБВ) оценивали по числу колониеобразующих единиц (KOE) МБТ на плотных средах: скудное - при КОЕ менее 100, массивное - КОЕ больше 100. Цитотоксичность МБТ определяли на модели активации гибели макрофагов (цитотоксический тест) с использованием перевиваемой линии моноцитоподобных клеток человека THP-I [12] в нашей модификации [5].

Для оценки остроты воспаления исследовали в сыворотке крови белки острой фазы - церулоплазмин (ЦП - методом Равина), гаптоглобин (ГП), С-реактивный белок (СРБ) и орозомукоид (АГП) с использованием наборов фирмы «Termo Fisher Scientific»,

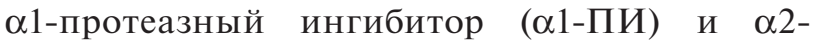
макроглобулин ( $\alpha 2-\mathrm{M \Gamma )}$ с использованием синтетического субстрата трипсина $\mathrm{N}-\alpha$-бензоилL-аргининпаранитроанилида [10].

Тяжесть и активность процесса оценивали по уровню неоптерина (Неоп), используя иммуноферментный набор «MP Biomedicals Germany $\mathrm{GmbH»} \mathrm{при} \mathrm{чувствительности} \mathrm{метода} \mathrm{выше}$ 1,2 нмоль/л, активности аденозиндезаминазы (АДА) с использованием метода G. Giusti [20], эластазоподобной (ЭП) активности крови методом L. Visser, E.R. Blout [26].

Распространенность процесса оценивалась рентгенологически по числу пораженных сегментов: при поражении 1-2 сегментов процесс расценивался как ограниченный, 3-5 сегментов - как распространенный (40,5 и 59,5\% случаев соответственно).

С учетом цели исследования в качестве группирующих факторов использовали: 1) генотипы выделенных МБТ; 2) эффективность трехмесячной противотуберкулезной терапии. В первом случае были сформированы две группы: первую составили 22 пациента, выделяющих МБТ семейства Beijing (9 мужчин, 13 женщин, 18-44 лет, медиана - 27 лет), вторую - 20 больных, выделяющих МБТ семейств LAM, T, U, H, X (иные генотипы) (7 мужчин, 13 женщин, в возрасте 18-74 лет, медиана - 31 год). Эффективность терапии, назначавшейся с учетом данных о наличии или отсутствии МЛУ, которые были 
получены молекулярно-генетическим методом, оценивали ретроспективно через 3 месяца лечения по динамике клинико-рентгенологических и бактериологических данных. Эффект терапии расценивался как «значительное улучшение» при абациллировании, ликвидации полостей распада и клинических признаков интоксикации и как «улучшение» - при сохранении полостей распада на фоне абациллирования и уменьшения признаков интоксикации.

Для статистического анализа данных, представленных в виде медианы и колебаний индивидуальных значений показателей, использован пакет прикладных программ Statistica 6.0. Для оценки степени различий показателей использованы коэффициент ковариации, непараметрический U-критерий ВилкоксонаМанна-Уитни, для проверки значимости корреляционных зависимостей - критерий Фишера, для дифференциации групп по совокупности показателей - пошаговый дискриминантный анализ.

\section{Результаты}

Группы I (Beijing) и II (иные генотипы) возбудителя туберкулеза были сходными по признаку массивности бактериовыделения и уровню цитотоксичности изолятов МБТ (табл. 1). Существенное различие установлено в отношении лекарственной чувствительности МБТ к противотуберкулезным препаратам: в случаях выделения МБТ генотипа Beijing они в 2,4 раза чаще оказывались резистентными ( $\mathrm{p}=$ 0,018). При этом у данной категории больных во всех случаях констатировали множественную лекарственную устойчивость (МЛУ), тогда как у больных II группы МЛУ отмечена только в двух случаях, а устойчивость к одному-двум препаратам - в 4. В обеих группах обнаружена корреляция МБВ и уровня цитотоксичности для пациентов с МБТ генотипа Beijing $-\mathrm{r}=0,49$ $(\mathrm{p}=0,019)$, II группы $-\mathrm{r}=0,44(\mathrm{p}=0,05)$.

В то же время больные сопоставляемых групп различались и по такой рентгенологической характеристике как распространенность поражения легких: в I группе доля лиц с поражением 3 и более сегментов оказалась большей, чем во II (82 против 35\%; $\mathrm{p}=0,009$ ).

Межгрупповые различия, ассоциированные с генотипическими особенностями МБТ, выявлены и в отношении результативности противотуберкулезной терапии: «значительное улучшение» имело место у $41 \%$ больных І группы и у $70 \%$ больных II группы ( $<0,05)$. При этом у больных II группы установлена тесная связь между эффективностью терапии и степенью цитотоксичности МБТ ( $\mathrm{r}=0,56 ; \mathrm{p}=0,01)$, и распространенностью поражения легких $(\mathrm{r}=0,45 ; \mathrm{p}=0,03)$ при отсутствии зависимости от лекарственной чувствительности МБТ $(\mathrm{r}=-0,19 ; \mathrm{p}=0,42)$.

\section{ТАБЛИЦА 1. БИОЛОГИЧЕСКИЕ СВОЙСТВА МБТ В СОПОСТАВЛЯЕМЫХ ГРУППАХ БОЛЬНЫХ В ЗАВИСИМОСТИ ОТ ГЕНОТИПА}

\begin{tabular}{|l|c|c|}
\hline \multicolumn{1}{|c|}{$\begin{array}{c}\text { Биологические } \\
\text { свойства МБТ }\end{array}$} & $\begin{array}{c}\text { I } \\
\text { (n = 22) }\end{array}$ & $\begin{array}{c}\text { Групп } \\
\text { (n = 20) }\end{array}$ \\
\cline { 2 - 3 } & 27 & 40 \\
\hline $\begin{array}{l}\text { Бактериовыделение: } \\
\text { - скудное } \\
\text { - массивное }\end{array}$ & 73 & 60 \\
\hline $\begin{array}{l}\text { Цитотоксичность МБТ: } \\
\text { - низкая } \\
\text { - высокая }\end{array}$ & 54,5 & 40 \\
\hline $\begin{array}{l}\text { Чувствительность } \\
\text { к противотуберкулезным } \\
\text { препаратам }\end{array}$ & $27^{\star *}$ & 60 \\
\hline
\end{tabular}

Примечания. * Встречаемость биологических свойств указана в процентах; *夫 различие существенное - $\mathrm{p}<0,05$.

Анализ вариантов эффективности терапии в зависимости от генотипов МБТ обнаружил значимую ассоциированность последних только с их цитотоксичностью $\left(\chi^{2}=11,658 ; \mathrm{df}=3 ; \mathrm{p}=\right.$ 0,0086). У больных I группы (Beijing) при низкой и высокой цитотоксичности «значительное улучшение» в итоге трехмесячной терапии наблюдалось соответственно в 58 и $20 \%$ случаев, а в аналогичных случаях при МБТ иных генотипов доля больных с такими результатами лечения составила 100 и $50 \%$.

Те же принципы были использованы при оценке особенностей системного воспалительного ответа организма, индуцируемого МБТ рассматриваемых генотипов. Согласно результатам исследования десяти биохимических показателей, использованных в качестве маркеров активности и тяжести воспалительного процесса, в целом больные обеих групп сходны по значениям медиан признаков и, судя по величинам коэффициентов ковариации, их дисперсии (табл. 2).

Поскольку в обеих группах, сформированных по признаку принадлежности МБТ к семейству Beijing или иному генотипу, регистрировались случаи с различной результативностью терапии, в каждой из них были выделены подгруппы со «значительным улучшением» и с «улучшением» - А и Б соответственно (табл. 3). Больным подгруппы I-A оказался свойственен значимо превышающий референтный уровень $\alpha 1-П И$, а в подгруппе II-A - уровень неоптерина.

Более разнообразные изменения выявлены среди больных, эффективность терапии у которых расценивалась как «улучшение» (подгруппы І-Б и ІІ-Б): в обеих подгруппах отмечены более высокие по сравнению с референтными значениями уровень ЦП и активности АДА, а в подгруппе І-Б кроме них и уровни ГП, АГП и $\alpha 1-П И$. 


\section{ТАБЛИЦА 2. ЗНАЧЕНИЯ БИОХИМИЧЕСКИХ ПОКАЗАТЕЛЕЙ ОБСЛЕДОВАННЫХ БОЛЬНЫХ С УЧЕТОМ ГЕНОТИПА ШТАММА МБТ*}

\begin{tabular}{|c|c|c|}
\hline Показатели & I группа & II группа \\
\hline СРБ, Мг/л & $\begin{array}{c}8,3 \\
(4,2-162,3 ; 27,0 \%)\end{array}$ & $\begin{array}{c}10,1 \\
(4,9-49,9 ; 36,0 \%)\end{array}$ \\
\hline ГП, г/л & $\begin{array}{c}1,36 \\
(0,19-2,56 ; 11,0 \%)\end{array}$ & $\begin{array}{c}1,22 \\
(0,59-3,6 ; 11,8 \%)\end{array}$ \\
\hline ЦП, г/л & $\begin{array}{c}0,38 \\
(0,17-0,61 ; 5,0 \%)\end{array}$ & $\begin{array}{c}0,37 \\
(0,25-0,55 ; 4,3 \%)\end{array}$ \\
\hline АГП, г/л & $\begin{array}{c}1,07 \\
(0,56-1,89 ; 8,0 \%)\end{array}$ & $\begin{array}{c}1,06 \\
(0,51-1,73 ; 7,0 \%)\end{array}$ \\
\hline Альб., г/л & $\begin{array}{c}45,25 \\
(38,7-58,6 ; 12 \%)\end{array}$ & $\begin{array}{c}40,9 \\
(35,0-62,7 ; 14,9 \%)\end{array}$ \\
\hline ф1-ИП, нмоль/л & $\begin{array}{c}2,24 \\
(1,3-3,55 ; 4,3 \%) \\
\end{array}$ & $\begin{array}{c}1,99 \\
(0,63-2,68 ; 7,5 \%)\end{array}$ \\
\hline а2-МГ, нмоль/л & $\begin{array}{c}2,1 \\
(1,43-2,47 ; 3,5 \%)\end{array}$ & $\begin{array}{c}1,76 \\
(1,25-3,3 ; 6,3 \%)\end{array}$ \\
\hline Эл, мЕ & $\begin{array}{c}163,0 \\
(86,9-217,3 ; 5,1 \%) \\
\end{array}$ & $\begin{array}{c}173,9 \\
(87,9-282,5 ; 6,5 \%)\end{array}$ \\
\hline АДА, ед/л & $\begin{array}{c}18,2 \\
(7,8-49,0 ; 9,1 \%)\end{array}$ & $\begin{array}{c}15,9 \\
(11,2-55,5 ; 5,5 \%)\end{array}$ \\
\hline Нп, нмоль/л & $\begin{array}{c}6,5 \\
(1,0-11,8 ; 8,1 \%)\end{array}$ & $\begin{array}{c}6,72 \\
(4,74-22,9 ; 11,0 \%)\end{array}$ \\
\hline
\end{tabular}

Примечание. * Приведены значения медианы, пределы индивидуальных колебаний и коэффициент вариации (CV - \%).

Больным всех подгрупп, то есть независимо от генотипа МБТ и результативности терапии, свойственно значимое снижение по сравнению с референтными величинами уровня $\alpha 2-$ МГобщ.

Таким образом, в ходе анализа выявлено, что больных подгрупп Б, то есть с худшим эффектом трехмесячной противотуберкулезной терапии, отличают от больных «со значительным улучшением» большая выраженность изменений маркеров системного воспалительного ответа, особенно в случаях с МБТ генотипа Beijing (подгруппа І-Б).

Различия, определяемые генотипом МБТ, отражают и неоднородность плеяд корреляций эффектов противотуберкулезной терапии с включенными в анализ характеристиками МБТ и БОФ. Для больных I группы выявлена существенная связь только с уровнями ГП ( $\mathrm{r}=$ $0,676 ; \mathrm{p}=0,0008)$ и ЦП $(\mathrm{r}=0,438 ; \mathrm{p}=0,047)$. Для больных II группы в плеяду корреляций вошли признаки: цитоксичность МБТ (r = 0,556; $\mathrm{p}=$ $0,011)$ Ц П ( $\mathrm{r}=0,58 ; \mathrm{p}=0,007)$, АДА ( $\mathrm{r}=0,445$; $\mathrm{p}=0,049)$, Неоп. $(\mathrm{r}=-0,48 ; \mathrm{p}=0,032)$. Соответственно вклад в характеристику изучаемых явлений каждого из вошедших в плеяды показателей, оцениваемый по величинам коэффициентов детерминации $\left(\mathrm{r}^{2}\right)$, составляет для больных I группы с МБТ генотипа Beijing 0,457 для ГП и 0,192 для ЦП, а для больных II группы 0,336 для ЦП, 0,31 для цитотоксичности МБТ, 0,23 для неоптерина и 0,2 для АДА.

Полученные данные предполагают неоднозначность вклада обсуждаемых маркеров в воспалительный ответ организма больного, особенности которого определяют наряду с характеристиками МБТ эффективность противотуберкулезной терапии. Подтверждением сказанному явились результаты дискриминантного анализа совокупности всех изучавшихся биохимических показателей. Общим для дискриминантных функций обеих анализируемых групп оказалось включение показателей ГП, ЦП, Эл и АДА. Кроме того дискриминантную функцию больных группы Beijing отличает включение признака $\alpha 2-$ МГобщ, а больных II группы - признака Альб.

\section{ТАБЛИЦА З. ИСХОДНЫЕ БИОХИМИЧЕСКИЕ ХАРАКТЕРИСТИКИ БОЛЬНЫХ С УЧЕТОМ ГЕНОТИПА МБТ И ЭФФЕКТИВНОСТИ ПРОТИВОТУБЕРКУЛЕЗНОЙ ТЕРАПИИ*}

\begin{tabular}{|c|c|c|c|c|}
\hline \multirow{2}{*}{ Показатели } & \multicolumn{2}{|c|}{ Группа I-Beijing } & \multicolumn{2}{|c|}{ Группа II - иные генотипы } \\
\hline & A & Б & A & Б \\
\hline СРБ, мг/л & $6,4(4,9-134,1 ; 172 \%)$ & $38,3(4,2-162,3 ; 100 \%)$ & $10,4(5,3-49,9 ; 154 \%)$ & $7,96(4,9-17,9 ; 52 \%)$ \\
\hline ГП, г/л & $0,83(0,19-1,38 ; 47 \%)$ & $1,95(0,79-2,56 ; 31 \%)^{\star, \star \star}$ & $0,95(0,59-1,85 ; 37 \%)$ & $1,64(0,81-3,6 ; 5,8 \%)$ \\
\hline ЦП, г/л & $0,36(0,17-0,46 ; 26 \%)$ & $0,42(0,33-0,61 ; 21 \%)^{\star, * *}$ & $0,32(0,25-0,45 ; 15 \%)$ & $0,43(0,35-0,55 ; 18 \%)^{\star, * *}$ \\
\hline АГП, г/л & $1,06(0,56-1,82 ; 39 \%)$ & $1,41(0,56-1,89 ; 32 \%)^{\star}$ & $1,09(0,51-1,73 ; 36 \%)$ & $1,06(0,74-1,35 ; 23 \%)$ \\
\hline Альб., г/л & $42,5(38,7-54,4 ; 12 \%)$ & $45,3(39,6-58,6 ; 12,5 \%)$ & $41,15(37,5-50,7 ; 7,7 \%)$ & $40,35(35,0-62,7 ; 24,1 \%)$ \\
\hline$\alpha 1-И П$, нмоль/л & $2,16(1,3-2,43 ; 19 \%)^{*}$ & $2,36(1,63-3,55 ; 20 \%)^{*}$ & $1,94(0,63-2,68 ; 33 \%)$ & $2,06(0,74-2,24 ; 31 \%)$ \\
\hline$\alpha 2-\mathrm{MГ,} \mathrm{нмоль/л}$ & $1,86(1,57-2,4 ; 17 \%)$ & $2,12(1,43-2,47 ; 18 \%)^{\star}$ & $1,76(1,25-3,3 ; 39 \%)^{\star}$ & $1,75(1,44-1,98 ; 12 \%)^{\star}$ \\
\hline Эл, мE & $173,9(119,5-217,3 ; 19 \%)$ & $130,0(86,9-217,0 ; 28 \%)$ & $173,9(87,9-282,5 ; 32 \%)$ & $173,9(130,4-239,1 ; 23 \%)$ \\
\hline АДА, ед/л & $15,2(14,0-27,0 ; 27 \%)$ & $20,8(7,8-49,0 ; 48 \%)^{\star}$ & $14,4(11,2-28,6 ; 29 \%)$ & $\begin{array}{c}17,7(14,1-55,5 ; 65 \%)^{\star, \star \star} \\
p=0,05\end{array}$ \\
\hline Нп, нмоль/л & $5,1(3,0-7,5 ; 26 \%)$ & $6,7(1,0-11,8 ; 42 \%)$ & $7,1(5,9-22,9 ; 49 \%)^{*}$ & $6,7(4,74-7,1 ; 16 \%)^{\star \star}$ \\
\hline
\end{tabular}

Примечания. *) Приводятся значения медианы, пределы индивидуальных колебаний, коэффициент вариации (СV - \%); * значимое различие с референтным значением; ** значимые внутригрупповые различия у больных с различной эффективностью терапии: А — «значительное улучшение», Б - «улучшение». 
Соответственно дискриминантные функции, включающие указанные показатели, имеЮТ вид:

- для больных общей совокупности (без учета генотипов МБТ):

$$
\mathrm{y}=22,927 \times Ц \Pi+4,542 \times \Gamma \Pi+0,162 \text { АДА - }
$$$$
0,036 \times \text { ЭЛ - 12,993; }
$$

- для больных I группы (с МБТ типа Beijing):

$\mathrm{y}=37,96 \times$ ЦП + 5,585 × ГП + 0,233 × АДА $0,048 \times$ Эл $+8,77 \times \alpha 2-$ МГ $-36,437$;

- для больных II группы (с МБТ других генотипов):

$\mathrm{y}=42,88 \times Ц П+7,634 \times \Gamma \Pi+0,996 \times$ АДА $0,084 \times$ Эл $-1,462 \times$ Альб $+26,151$.

При этом значения у $<0$ определяют вероятность «значительного улучшения», а у > 0 - «улучшения» после трехмесячной противотуберкулезной терапии. Соответственно установленная точность классификации (прогнозирования) составила для общей группы 92,3\%, для больных I группы - 95,2\% и II группы - $100 \%$.

Иллюстрирует вышеизложенное соотношение зон (эллипсов) рассеяния индивидов с ИТЛ легких рассматриваемых подгрупп, сформированных с учетом генотипов МБТ и результатов противотуберкулезной терапии (рис., II обложка). Расположение эллипсов с высокой точностью отражает возможности дифференциации:

- обоих вариантов эффективности противотуберкулезной терапии независимо от генотипов МБТ;

- ожидаемой эффективности терапии в условиях отсутствия данных о генотипе МБТ при использовании назначений наиболее информативных биомаркеров воспалительного ответа.

В последнем случае дискриминантная функция ограничивается признаками ГП, ЦП, Эл и АДА, общими и для всех выше обсуждавшихся дискриминантных функций, чем обеспечивается 92,3\% точность классификации.

\section{Обсуждение}

В последние годы изучение особенностей формирования и течения туберкулезного процесса в легких закономерно связывается с детализацией соотношений составляющих системы «патоген-хозяин». В клинической фтизиатрии, как правило, обсуждается характер индуцируемой МБТ воспалительной реакции организма, выражающейся в мобилизации систем клеточной и гуморальной защиты, в сопоставлении с биологическими свойствами МБТ [13]. Именно такой комплексный подход признается наиболее перспективным для разработки новых более совершенных вакцин [15]. Однако в силу методических трудностей исследования в данном направлении относительно немногочисленны. К числу этих трудностей относятся сложности формирования клинически однородных групп больных по форме процесса в легких, его длительности, отсутствию или характеру предшествующей терапии, ее эффективности и другим характеристикам, способным отразиться на системном воспалительном ответе организма больного. При оценке последнего до сих пор, как правило, ограничиваются изучением, без должного учета характеристик МБТ, биохимических показателей - реактантов воспаления (белков острой фазы - БОФ), идентификация которых широко доступна [4].

Принято считать, что изменения БОФ отражают активность и тяжесть процесса, его динамику на фоне химиотерапии [4, 8]. Однако при этом не всегда принимается во внимание, что продукция отдельных БОФ может не совпадать как по срокам эволюции воспалительной реакции, так и по выраженности, что явилось основанием для использования констелляций БОФ, обеспечивающих их большую диагностическую и прогностическую информативность [3].

Сопоставление многокомпонентной воспалительной реакции организма, индуцируемой МБТ, до сих пор редко включают оценку вирулентности возбудителя. В последние годы обращается внимание на ее связь с генетическими особенностями МБТ, определяющими различия в скорости роста МБТ, индуцируемой ими активности макрофагов, продукции провоспалительных цитокинов [18, 25, 28, 31]. В частности, особо выделяются МБТ генотипа Beijing, для которого характерна бо́льшая частота лекарственной резистентности, высокой вирулентности возбудителя, тяжести поражения легких и худшего исхода заболевания [1, 14].

В связи со сказанным в настоящем исследовании особое внимание обращалось на рандомизацию групп как по форме процесса (ИТЛ), так и по отсутствию предшествующей терапии. В итоге в исследование было включено 42 больных впервые выявленным нелеченным ИТЛ. В качестве группирующих факторов использованы генотипы МБТ (Beijing и иные) и результативность трехмесячной противотуберкулезной терапии, а в качестве результирующих признаков - 10 биохимических маркеров ответа организма на индуцированный МБТ воспалительный процесс в легких (БОФ).

С обсуждаемыми в литературе данными о более тяжелом течении туберкулеза легких, индуцируемого МБТ генотипа Beijing, сочетаются и полученные нами результаты, свидетельствующие о преобладании среди этой категории больных лиц с большей распространенностью поражения (82,0 против $35,0 \%)$, с МБТ с множественной лекарственной устойчивостью $(73,0$ против 30,0\%) и меньшей долей случаев со значительным улучшением после адекватной (трех- 
месячной) противотуберкулезной терапии (41,0 против 70,0\%). При этом эффект терапии в общей популяции (42 пациента) обследованных больных не зависел от лекарственной устойчивости МБТ $(\mathrm{r}=0,1 ; \mathrm{p}=0,62)$.

Поскольку у больных с МБТ рассматриваемых генотипов возможны оба варианта результатов противотуберкулезной терапии, закономерен вопрос, насколько пациенты I и II групп различаются по особенностям структуры воспалительного ответа организма (табл. 3). Результаты настоящего исследования свидетельствуют, что «значительное улучшение» в итоге трехмесячной противотуберкулезной терапии у больных обеих групп ассоциируется с отсутствием отличий исходных значений БОФ от референтных. В то же время в случае генотипа Beijing для больных со вторым, менее благоприятным вариантом эффективности терапии - «улучшение» - установлено повышение 6 из 10 биохимических показателей по сравнению с референтными их значениями, в подгруппе иных генотипов -3 из 10. Таким образом, констатация у больных впервые выявленным нелеченным ИТЛ уровней БОФ в пределах референтных значений позволяет предполагать высокую степень вероятности «значительного улучшения» в итоге трехмесячного лечения. Возможности дифференциации больных ИТЛ легких с ожидаемой различной эффективностью терапии по исходным значе- ниям БОФ нашли подтверждение в результатах дискриминантного анализа, в ходе которого выделена общая констелляция из четырех ассоциированных с эффектом терапии биохимических маркеров воспаления - ГП, ЦП, Эл и АДА. При этом не установлено зависимости прогностической информативности этих показателей от генотипов и других биологических свойств МБТ.

Полученные результаты подтверждают представление о неоднозначности отдельных биохимических маркеров ввиду различия их функций, как в формировании воспалительного процесса, так и в реализации на этапах его эволюции противовоспалительного эффекта. Этим, на наш взгляд, и обосновывается целесообразность оценки характера воспалительного ответа организма больного туберкулезом легких по совокупности показателей, что обеспечивает наиболее точный прогноз. Выделенная в настоящем исследовании констелляция из четырех показателей (ГП, ЦП, Эл и АДА), оказалась в сходной степени прогностически информативна в отношении обоих обсуждавшихся вариантов эффекта трехмесячной противотуберкулезной терапии независимо от характеристик МБТ. В связи с этим есть основания предполагать, что в системе «патоген-хозяин» преобладает значимость составляющей «хозяин», отражающей ответ организма на индуцируемый МБТ воспалительный процесс.

\title{
MYCOBACTERIUM TUBERCULOSIS BIOLOGICAL PROPERTIES AND CHARACTERISTICS OF THE INFLAMMATORY REACTION IN PATIENTS WITH INFILTRATIVE PULMONARY TUBERCULOSIS
}

Titarenko O.T., Dyakova M.E., Manicheva O.A., Esmedlyaeva D.S., Dogonadze M.Z., Alexeyeva N.P., Melnikova N.N.

\section{St. Petersburg Research Institute of Phthisiopulmonology, St. Petersburg, Russian Federation}

\begin{abstract}
Host-pathogen relations were analyzed on basis of the results of examinations of 42 patients with newly diagnosed, previously untreated infiltrative pulmonary tuberculosis (IPT) with regard for the biological characteristics of $M y$ cobacterium tuberculosis (MBT) and the biomarkers of the inflammatory reaction - the acute phase proteins (APPs). The genotypes of MBT (Beijing and the others) and the efficacy of three-month antituberculosis therapy were used as the grouping factors. Genotype Beijing MBT patients were significantly often characterised by multiple drug resistant, had widespread pulmonary damage and association of MBT cytoxicity with the effect of therapy. The patients with the best postreatment effect had initial (pretreatment) APPs levels in the range of the referent ones. These conclusions were confirmed by analysis of the correlation pleads of the characteristics of the "host-pathogen" system and their discriminant analysis with regard for MBT genotypes and results of antituberculosis three-month therapy. It was shown that the constellation of four host's APP characteristics (haptoglobin, ceruloplasmin, elastase and adenoaminase activities) has above $90 \%$ prognostic efficacy of treatment in spite of MBT genotype. It is suggested that in IPT patients the first component of the "host-pathogen" system reflecting the reaction of the patient's organism to the MBT induced inflammatory process is more prognostically important.
\end{abstract}

Key words: tuberculosis, acute phase proteins, genotype, virulence. 


\section{Authors:}

Titarenko 0.T. $ه, P h D$ (Medicine), Head of the Laboratory of the Pathogenetic Researches, St. Petersburg Research Institute of Phthisiopulmonology;

194064, Russian Federation, St. Petersburg, Polytechnicheskaya str., 32.

Phone: +7 (812) 297-86-31. Fax: +7 (812) 297-16-26.

E-mail: olga-titarenko39@yandex.ru

Dyakova M.Y., PhD (Biology), Senior Researcher, Laboratory of the Pathogenetic Researches, St. Petersburg Research Institute of Phthisiopulmonology, St. Petersburg, Russian Federation;

Manicheva O.A., PhD, MD (Biology), Leading Researcher, Laboratory of the Etiologic Diagnostics, St. Petersburg Research Institute of Phthisiopulmonology, St. Petersburg, Russian Federation;

Esmedlyaeva D.S., PhD (Biology), Senior Researcher, Laboratory of the Pathogenetic Researches, St. Petersburg Research Institute of Phthisiopulmonology, St. Petersburg, Russian Federation;

Dogonadze M.Z., PhD (Biology), Senior Researcher, Laboratory of the Etiologic Diagnostics, St. Petersburg Research Institute of Phthisiopulmonology, St. Petersburg, Russian Federation;

Alexeyeva N.P., PhD (Physics and Mathematics), Programmer, Department of the Scientific Technical Information, St. Petersburg Research Institute of Phthisiopulmonology, St. Petersburg, Russian Federation;

Perova T.L., Researcher, Laboratory of the Pathogenitic Researches, St. Petersburg Research Institute of Phthisiopulmonology, St. Petersburg, Russian Federation;

Melnikova N.N., PhD (Medicine), Senior Researcher, Laboratory of the Etiologic Diagnostics, St. Petersburg Research Institute of Phthisiopulmonology, St. Petersburg, Russian Federation.

\section{Список литературы/References}

1. Барнаулов А.О. Клиническое значение и эффективность лечения туберкулеза легких в зависимости от степени цитотоксичности возбудителя: автореф. дис. ... канд. мед. наук. СПб., 2010. 22 с. [Barnaulov A.O. Klinicheskoe znachenie i effektivnost' lecheniya tuberkuleza legkikh v zavisimosti ot stepeni tsitotoksichnosti vozbuditelya: avtoref. dis. ... kand. med. nauk [Clinical value and treatment efficacy of pulmonary tuberculosis in dependence on degree of the pathogen cytotoxicity. Autoref. Med. Sci. diss]. SPb., 2010, 22 p.].

2. Глотова Е.В., Абдуллаев Р.Ю., Чеботарева Т.В., Облогина Л.И. Оценка синдрома системного воспалительного ответа у больных с впервые выявленным туберкулезом легких // Туберкулез и болезни легких. 2011. № 11. С. 8-11. [Glotova E.V., Abdullaev R.Yu., Chebotareva T.V., Oblogina L.I. Otsenka sindroma sistemnogo vospalitel'nogo otveta u bol'nykh s vpervye vyyavlennym tuberkulezom legkikh [Estimation of the systemic inflammatory response syndrome in patients with newly diagnosed pulmonary tuberculosis]. Tuberkulez i bolezni legkikh = Tuberculosis and Lung Diseases, 2012, no. 11, pp. 8-11.].

3. Елькин А.В., Титаренко О.Т., Эсмедляева Д.С., Дьякова М.Е., Алексеева Н.П., Перова Т.Л. Оценка риска послеоперационных инфекционных осложнений у больных фиброзно-кавернозным туберкулезом легких // Туберкулез и болезни легких. 2009. № 5. C. 31-33. [El’kin A.V., Titarenko O.T., Esmedlyaeva D.S., D'yakova M.E., Alekseeva N.P., Perova T.L. Otsenka riska posleoperatsionnykh infektsionnykh oslozhneniy u bol'nykh fibrozno-kavernoznym tuberkulezom legkikh [Assessment of postsurgery infections complications rick in patients with fibro-covernous pulmonary tuberculosis]. Tuberkulez i bolezni legkikh = Tuberculosis and Lung Diseases, 2009, no. 5, pp. 31-33.].

4. Каминская Г.О., Абдуллаев Р.Ю., Мартынова Е.В., Серебряная Б.А., Комиссарова О.Г. Синдром системного воспалительного ответа при туберкулезе легких // Туберкулез и болезни легких. 2009. № 11. С. 40-48. [Kaminskaya G.O., Abdullaev R.Yu., Martynova E.V., Serebryanaya B.A., Komissarova O.G. Sindrom sistemnogo vospalitel'nogo otveta pri tuberkuleze legkikh [Syndrome of systemic inflammatory response in pulmonary tuberculosis]. Tuberkulez $i$ bolezni legkikh $=$ Tuberculosis and Lung Diseases, 2009, no. 11, pp. 40-48.].

5. Маничева О.А., Нарвская О.В., Мокроусов И.В., Вязовая А.А., Журавлев В.Ю., Барнаулов А.О., Догонадзе М.З., Оттен Т.Ф., Вишневский Б.И. Лекарственная устойчивость, жизнеспособность и вирулентность in vitro штаммов Mycobacterium tuberculosis различных генотипов // Инфекция и иммунитет. 2011. Т. 1, № 4. С. 341-348. [Manicheva O.A., Narvskaya O.V., Mokrousov I.V., Vyazovaya A.A., Zhuravlev V.Yu., Barnaulov A.O., Dogonadze M.Z., Otten T.F., Vishnevskiy B.I. Lekarstvennaya ustoychivost', zhiznesposobnost' i virulentnost' in vitro shtammov Mycobacterium tuberculosis razlichnykh genotipov [Drug resistency, viability and virulence in vitro of the Mycobacterium tuberculosis strains of different genotypes]. Infektsiya i immunitet = Infection and Immunity, 2012, vol. 1, no. 4, pp. 341-348.].

6. Павлов В.А., Медвинский И.Д., Чучаев Ю.П., Сабодаш Е.В. Защитно-адаптивные механизмы при туберкулезной инфекции // Фтизиатрия и пульмонология. 2011. № 1. С. 42-54. [Pavlov V.A., Medvinskiy I.D., Chuchaev Yu.P., Sabodash E.V. Zashchitno-adaptivnye mekhanizmy pri tuberkuleznoy infektsii [Adaptive-protective mechanisms in case of tuberculosis infection]. Ftiziatriya i pul'monologiya = Phtisiology and Pulmonology, 2011, no. 1, pp. 42-54.].

7. Титаренко О.Т., Дьякова М.Е., Павлова М.В., Эсмедляева Д.С., Алексеева Н.П., Перова Т.Л. Клинико-лабораторные сопоставления в оценке прогноза лечения больных инфильтративным туберкулезом легких // Клиническая лабораторная диагностика. 2012. № 5. C. 31-34. [Titarenko O.T., D’yakova M.E., Pavlova M.V., Esmedlyaeva D.S., Alekseeva N.P., Perova T.L. Kliniko-laboratornye sopostavleniya v otsenke prognoza lecheniya bol ’nykh infil'trativnym tuberkulezom legkikh [The clinical laboratory comparison in the assessment of treatment prognosis in patients with infiltrative tuberculosis of lungs]. Klinicheskaya laboratornaya diagnostika = Clinical Laboratory Diagnostics, 2012, no. 5, pp. 31-34.].

8. Титаренко О.Т., Дьякова М.Е., Перова Т.Л., Ряснянская Т.Б. Активность аденозиндезаминазы и ее изоферментов у больных с различными формами туберкулеза // Туберкулез и болезни легких. 2002. № 3. C. 43-45. [Titarenko O.T., D`yakova M.E., Perova T.L., Ryasnyanskaya T.B. Aktivnost’ adenozindezaminazy i ee izofermentov u bol’nykh s razlichnymi formami tuberkuleza [Activity of adenosine deaminase and its isoenzymes in patients with different forms of tuberculosis]. Tuberkulez i bolezni legkikh $=$ Tuberculosis and Lung Diseases, 2002, no. 3, pp. 43-45.]. 
9. Almeida M.L., Barbieri M.A., Gurgel R.Q., Abdurrahman J.T. $\alpha 1$-acid glycoprotein and $\alpha 1$-antitrypsin as early markers of treatment response in patients receiving the intensive phase of tuberculosis therapy. Transactions of the Royal Society of Tropical Medicine and Hygiene, 2009, vol. 103, pp. 575-580.

10. Bogolyubova G.M., Sankovsky A.A., Sherbak J.G. A method of inactivating alpha 2 macroglobulin in blood plasma. Lab. Delo, 1988, no. 11, pp. 13-15.

11. Breen R.A.M., Leonard O., Perrin F.M.R., Smith C.J., Bhagani S., Cropley L., Lipman M.C.I. How good are systemic symptoms and blood inflammatory markers at defecting individuals with tuberculosis? Inf. J. Tuberc. Lung Dis., 2008, vol. 12, no. 1, pp. 44-49.

12. Castro-Garza J., Barrios-García H., Cruz-Vega D., Said-Fernandez S., Carranza-Rosales P., Molina-Torres C., Vera-Cabrera L. Use of a colorimetric assay to measure differences in cytotoxicity of Mycobacterium tuberculosis strains. J. Medical Microbiol., 2007, vol. 56, pp. 733-737.

13. Cooper A.M., Mayer-Barber K.D., Sher A. Role of innate cytokines in mycobacterial infection. Mucosal Immunology, 2011, vol. 4, no. 3, pp. 252-260.

14. Caws M., Thwaites G., Dunstan S., Hawn T.R, Lan N.T.N., Thuong N.T.T., Stepniewska K., Huyen M.N.T., Bang N.D., Loc T.H., Gagneux S., Soolingen D., Kremer K., Sande M., Small P., Anh P.T., Chinh N.T., Quy H.T., Duyen N.T.H., Tho D.Q., Hieu N.T., Torok E., Hien T.T., Dung N.H., Nhu N.T.Q., Duy P.M., Chau N.V., Farrar J. The influence of host and bacterial genotype on the development of disseminated disease with Mycobacterium tuberculosis. PLoS Pathog., 2008, vol. 4, pp. 1-9.

15. Dietrich J., Doherty M. Interaction of Mycobacterium tuberculosis with the host: consequence for vaccine development. APMIS, 2009, vol. 117, iss. 5-6, pp. 440-457.

16. Drobniewski F., Balabanova Y., Nikolayevsky V., Ruddy M., Kuznetzov S., Zakharova S., Melentyev A., Fedorin I. Drug-resistant tuberculosis, clinical virulence, and the dominance of the Beijing strain family in Russia. JAMA, 2005, vol. 293, no. 22, pp. $2726-2731$.

17. Forrellad M.A., Klepp L.I., Gioffré A., Sabio y García J., Morbidoni H.R., de la Paz Santangelo M., Cataldi A.A., Bigi F. Virulence factors of the Mycobacterium tuberculosis complex. Virulence, 2013, vol. 4, no. 1, pp. 3-66.

18. Hanekom M., Gey van Pittius N.C., McEvoy C.C., Victor T.C., Van Helden P.D., Warren R.M. Mycobacterium tuberculosis Beijing genotype: A template for success. Tuberculosis (Edinb.), 2011, vol. 91, no. 6, pp. 510-523.

19. Horita N., Miyazawa N., Yoshiyama T., Sato T., Yamamoto M., Tomaru K., Masuda M., Tashiro K., Sasaki M., Morita S., Kaneko T., Ishigatsubo Y. Development and validation of a tuberculosis prognostic score for smear-positive in-patients in Japan. J. Tuberc. Lung Dis., 2013, vol. 17, no. 1, pp. 54-60.

20. Giusti G. Methods of enzymatic analysis. Ed. H. Bergmeyer, New York, 1974, vol. 2, p. 1092.

21. Kamerbeek J., Schouls L., Kolk A., Van Agterveld M., Van Soolingen D., Kuiper S., Bunschoten A., Molhuizen H., Shaw R., Goyal M., Van Embden J. Simultaneous detection and strain differentiation of Mycobacterium tuberculosis for diagnosis and epidemiology. J. Clin. Microbiol., 1997, vol. 35, no. 4, pp. 907-914.

22. Manger I.D., Relman D.A. How the host «sees» pathogens: global gene expression resposes to infection. Curr. Opin. Immunol., 2000, vol. 12, pp. 215-218.

23. Tang C., Holden D. Pathogen virulence genes: impliations for vaccines and drug therapy. Brit. Med. Bull., 1999, vol. 55, pp. 387-400.

24. Thwaites G., Caws M., Chau T.T., D’Sa A., Lan N.T.N., Huyen M.N.T., Gagneux S., Anh P.T.H., Tho D.Q., Torok E., Nhu N.T.Q., Duyen N.T.H., Duy P.M., Richenberg J., Simmons C., Hien T.T., Farrar J. Relationship between Mycobacterium tuberculosis genotype and the clinical phenotype of pulmonary and meningeal tuberculosis. J. Clin. Microbiol., 2008, vol. 46, pp. 1363-1368.

25. Tsolaki A.C., Gagneux S., Pym A.S., Goguet de la Salmoniere Y-Ol. Genomic deletions classify the Beijing/W strains as a distinct genetic lineage of Mycobacterium tuberculosis. J. Clin. Microbiol., 2005, vol. 43, pp. 3185-3191.

26. Visser L., Blout E.R. The use of P-nitrophenyl-N-tertbutyloxylcarbonyl L-alaninate as substate for elastase. New York, 1972 , p. 919.

27. Visser M.E., Stead M.C., Walzl G., Warren R., Schomaker M., Grewal H.M.S., Swart E.C., Maartens G. Baseline predictors of sputum culture conversion in pulmonary tuberculosis: importance of cavities, smoking, time to detection and W-Beijing genotype. PLoS One, 2012, vol. 7, pp. 1-7.

28. Salahuddin N., Tianveer M., Rao N., Akram S., Hasan Z., Hasan R. Mycobacterium tuberculosis genotypes in patients developing pulmonary tuberculosis related acute respiratory distress syndrome. Sri Lanka. J. Crit. Care, 2011, vol. 2, pp. 20-24.

29. Sun Y.J., Ong A.K.Y., Lim T.K., Heng Ho B.C., Seah G.T., Paton N. Tuberculosis associated with Mycobacterium tuberculosis Beijing and non-Beijing genotypes: a clinical and immunological compatison. BMC Infect. Dis., 2006, vol. 6, pp. 105-110.

30. Swith J. Mycobacterium tuberculosis pathogenesis and molecular determinants of virulence. Clin. Microbiol. Rev., 2003, vol. 16, no. 3, pp. 463-496.

31. Wang C., Peyron P., Mestre O., Kaplan G., Van Soolingen D., Gao Q., Gicquel B., Neyrolles O. Innate immune response to Mycobacterium tuberculosis Beijing and other genotypes. PLoS One, 2010, vol. 5, pp. 13594. 


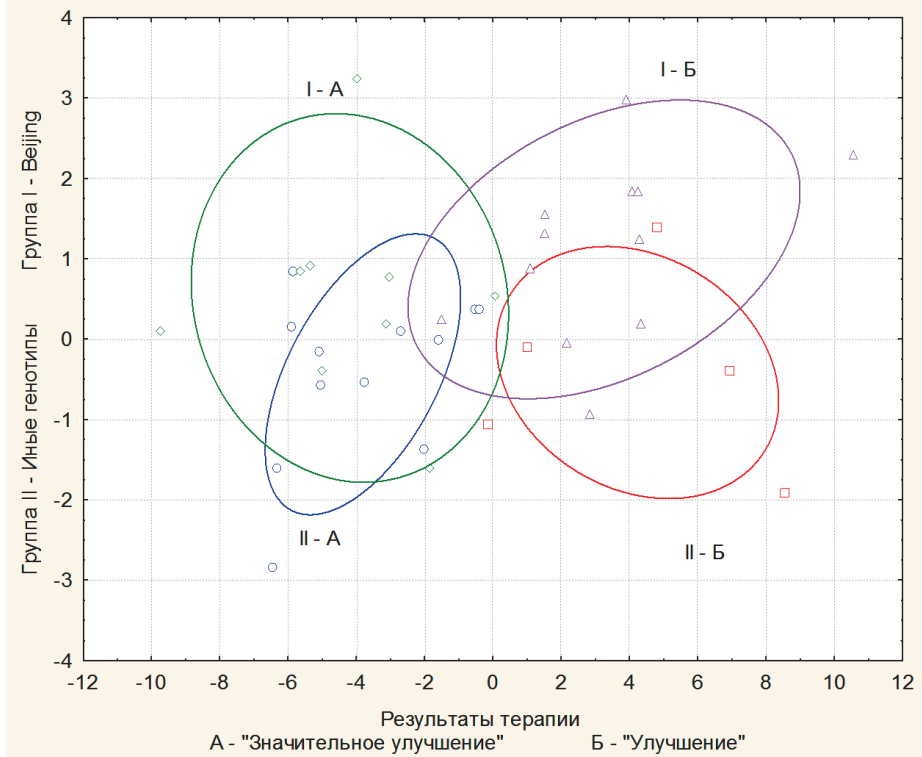

Рисунок. Диаграмма дискриминантных функций с учетом генотипа МБТ и результатов противотуберкулезной терапии 